\title{
REPRESENTAÇÕES E PEDAGOGIAS CULTURAIS OU “FORMAS DE FABRICAR SUJEITOS AMBIENTALMENTE COMPROMETIDOS”
}

\author{
Simoni Timm Hermes ${ }^{1}$, Elisane Maria Rampelotto ${ }^{2}$ \\ 1 Especialialista em Educação Ambiental (UFSM) \\ 2 Professora orientadora do Curso de Especialização em Educação Ambiental da UFSM
}

\section{RESUMO}

O presente artigo constitui-se pelo recorte da monografia de especialização intitulada "A natureza e a cultura na Revista Nova Escola: problematizando representações nas pedagogias culturais", desenvolvida no Curso a Distância de Especialização em Educação Ambiental, do Centro de Ciências Rurais, da Universidade Federal de Santa Maria. A investigação teve como objetivo geral problematizar as relações entre natureza e cultura produzidas na formação de professores/as nas pedagogias culturais. A Revista Nova Escola - Edição Especial - "Meio ambiente: conhecer para preservar" (2003), constituída por oito fascículos e um pôster, foi utilizada como materialidade desta pesquisa monográfica. As ferramentas da caixa de Michel Foucault, de autores relacionados aos Estudos Culturais e aos Estudos Culturais das Ciências, bem como a noção de risco de François Ewald serviram para construir as seguintes unidades de análise e discussão dos dados: "Representações culturais: dicotomia entre natureza e cultura", "Espaços-tempos escolares: passagens folclóricas pela Educação Ambiental" e "Pedagogias culturais: forças discursivas na gerência do risco". Estas unidades constituem o terceiro capítulo "Representações e pedagogias culturais ou "formas de fabricar sujeitos ambientalmente comprometidos" divulgado neste artigo. De certa forma, a análise e a discussão destas unidades permitiram compreender que tanto a rede discursiva antropocêntrica quanto a biocêntrica mantêm a lógica binária e utilitária na Revista Nova Escola; que a mídia impressa e digital em estudo se configura como um mecanismo de produção de verdades dos sujeitos escolares sobre si mesmos; que esta mídia divulga a necessidades das datas comemorativas, ou seja, das passagens folclóricas pela Educação Ambiental nos espaços-tempos escolares; que a tríade calculo, coletivo e capital permitem o gerenciamento dos riscos sócio-ambientais e produz efeitos na configuração das práticas pedagógicas desenvolvidas na educação escolar ou nas instâncias não.

Palavras-chave: Educação Ambiental, representações e pedagogias culturais.

\section{CONSIDERAÇÕES INICIAIS}

Na monografia de especialização intitulada "A natureza e a cultura na Revista Nova Escola: problematizando representações nas pedagogias culturais", no Curso a Distância de Especialização em Educação Ambiental, do Centro de Ciências Rurais, da Universidade Federal de Santa Maria, o entendimento de que a formação docente ocorre tanto em espaços formais como em espaços não-formais e informais, propiciou a definição do seguinte problema de pesquisa: como as representações da natureza e da cultura são produzidas na mídia impressa e digital destinada à formação dos professores e professoras? 
ISSN:

Mais do que aprofundar os conhecimentos em torno das questões ambientais na contemporaneidade, este problema suscitou a investigação das representações da natureza e da cultura numa revista que, em nível nacional e mensalmente, tem apresentado teorizações e propostas pedagógicas escolares e não-escolares. Tratou-se, então, de escolher como materialidade discursiva a Revista Nova Escola - Edição Especial - "Meio ambiente: conhecer para preservar" (2003) a fim de problematizar as relações entre natureza e cultura produzidas na formação de professores/as através desta pedagogia cultural. Mesmo que esta revista receba constantes atualizações, o objeto de estudo referido teve importante participação na vida de professores e professoras porque foi produzido num momento em que a "crise ambiental" tomou forma e nome e levou os meios de comunicação a divulgar e exigir comportamentos mais comprometidos dos sujeitos em formação.

O objetivo geral exposto pode ser desmembrado nas seguintes intenções: identificar as representações da natureza e da cultura produzidas na Revista Nova Escola - Edição Especial "Meio ambiente: conhecer para preservar" (2003); compreender as pedagogias divulgadas por esta instância cultural; problematizar as relações entre natureza e cultura veiculadas na formação de professores/as.

O problema e os objetivos expostos mostraram-se pertinentes na medida em que, na contemporaneidade, as questões ambientais são enfocadas, produzidas na educação de crianças ou jovens nas escolas de Educação Infantil e Anos Iniciais e Finais do Ensino Fundamental (ARAÚJO, 2004), mas, também, no processo de formação daqueles que atuam junto a essas crianças e jovens: os profissionais da educação. Dessa maneira, ao optar por uma materialidade discursiva presente e circulante entre professores e professoras e investigar as representações e as pedagogias culturais nela sugeridas, acredito ser viável questionar verdades no campo da educação e, especificamente, da educação ambiental.

Considerando que este artigo constitui-se pelo recorte desta monografia de especialização, especificamente, pelo terceiro capítulo "Representações e pedagogias culturais ou "formas de fabricar sujeitos ambientalmente comprometidos", abaixo, apresento a análise e a discussão dos dados presentes no referido trabalho acadêmico.

Os Estudos Culturais, os Estudos Culturais das Ciências, o pensamento filosófico de Michel Foucault e a noção de risco de François Ewald contribuíram para pensar e problematizar as relações entre a natureza e a cultura na materialidade discursiva da pesquisa.

Como se mostrou anteriormente, a Revista Nova Escola - Edição Especial - "Meio ambiente: conhecer para preservar" (2003), de circulação nacional e mensal, constitui-se como materialidade discursiva desta investigação. Como mostraram outras pesquisadoras (COSTA e SILVEIRA, 1997 apud ROCHA, 2000), esta revista, além de perpassar a formação inicial, circula entre professores e professoras atuantes na escola, em processo de formação continuada, pois apresenta textos com linguagem acessível e clara, apresentados ao lado de figuras e/ou fotos atrativas ao leitor.

A edição especial da revista em questão resultou da parceria entre o Instituto Unibanco e a Fundação Victor Civita. De abril a julho, de setembro a novembro do ano de dois mil e três, oito fascículos e um pôster acompanharam a revista. Os fascículos, em ordem de divulgação, foram assim nomeados: "A Terra está mesmo doente?", "As primeiras cidades, o primeiro lixo", "As fábricas e a poluição ambiental", "Consumo e desperdício, os pecados das grandes cidades", "O homem e a natureza no Brasil", "Amazônia e Pantanal, paraísos que podem ser salvos", "Brasil: a maior potência ecológica do mundo", "Um mundo melhor é possível". O pôster recebeu a denominação: "Bichos e plantas do Brasil: riquezas naturais". 
ISSN:

Os referidos fascículos ofertaram aos professores e professoras algumas informações sobre temas comuns na área da Educação Ambiental e trouxeram "Idéias para a sala de aula", ou seja, propostas de como trabalhar esses temas com crianças e jovens nas escolas.

No intuito de investigar as representações da relação natureza e cultura produzida nesta edição especial, utilizei a análise do documento (revista) e a pesquisa bibliográfica na coleta, análise e discussão dos dados da pesquisa bem como constituí quatro unidades de análise assim denominadas: "A natureza como bem, propriedade" versus "a natureza paradisíaca, intocável", "O homem como fonte e solução de todo mal", "Espaços-tempos escolares: passagens folclóricas pela Educação Ambiental" e "Pedagogias culturais: forças discursivas na gerência do risco". Estas unidades de análise permitem apresentar e discutir as representações culturais acerca da relação natureza e cultura nas pedagogias culturais que geram, põem em movimento pedagogias escolares.

\section{REPRESENTAÇÕES CULTURAIS: DICOTOMIA ENTRE NATUREZA E CULTURA}

\subsection{A "natureza como bem, propriedade" versus a "natureza paradisíaca, intocável"}

As representações de natureza e a cultura, materializadas nas pedagogias culturais, são perpassadas por relações de saber e poder que colocam em funcionamento tanto a rede discursiva antropocêntrica quanto a biocêntrica. Filosoficamente, essas concepções diferem em termos de princípios e práticas, mas, neste artigo, trata-se de analisar e discutir a produtividade destes discursos na manutenção de uma lógica binária e utilitária.

$\mathrm{O}$ antropocentrismo, indicando o homem como centro de todas as relações existenciais, narra a natureza como um "bem", uma "propriedade" a ser apropriada pela humanidade. Na utilização deste "bem/propriedade", cabe referir-se sempre às necessidades do homem que, para sua existência e sobrevivência, busca todos os recursos naquilo que, histórica e culturalmente, definimos como "natural". Então, eis uma das questões elaboradas por Amaral na sua Tese de Doutoramento:

Como falar sobre a natureza, ou mesmo problematizar a Educação Ambiental, sem antes problematizar a produção do antropocentrismo, do utilitarismo e de um certo 'classificacionismo', tomados como referências básicas no pensamento ocidental e a partir dos quais se falava, e ainda se fala, se concebia e, ainda, se concebe o mundo natural? (AMARAL, 2003, p. 42).

Uma manifestação contrária a esta primeira concepção teórico-filosófica aparece nos vários fascículos da Edição Especial da Revista Nova Escola como forma de crítica ao progresso e ao desenvolvimento irrestritos da sociedade moderna. Por isso, podemos encontrar narrativas como:

Hoje, no mundo todo, cresce a convicção de que a natureza e suas riquezas são um patrimônio de toda a humanidade. Todos têm direito a ar puro, água, qualidade de vida... São direitos ainda difusos, mas cada vez mais evidentes. (...) Acompanhe conosco, nas próximas edições da revista ESCOLA, a epopéia do domínio humano sobre a Terra (2003a, 4A). 
O homem sempre precisou dominar a natureza para sobreviver às chuvas torrenciais, às grandes secas, ao calor, ao frio e à ameaça da fome. Não foi por outro motivo que ele se fixou à terra e fundou os primeiros núcleos estáveis, que deram origem às cidades - e também aos desequilíbrios ecológicos (2003b, 1A).

(...) Revolução Industrial (...). Mas essa reviravolta fez uma vítima: o meio ambiente, no início sufocado pela fumaça das máquinas a vapor (que usavam carvão como combustível) e mais tarde aquecido e poluído pela queima de gases de derivados do petróleo. É dessa corrida do homem para o progresso, suas conquistas e as conseq6uências ambientais que este fascículo vai falar (2003c, 1A).

Essas narrativas da mídia impressa e digital em questão parecem relacionadas ao biocentrismo. Esta rede discursiva coloca o homem como destruidor desse "mundo natural" e, nesse sentido, prevê a total conservação e preservação da natureza. Nas palavras de Diegues, esse princípio e prática constituiriam o "mito moderno", ou seja,

um conjunto de representações existentes entre setores importantes do Conservacionismo ambiental de nosso tempo, portador de uma concepção biocêntrica das relações homem/natureza, pela qual o mundo natural tem direitos idênticos ao ser humano. Como corolário dessa concepção, o homem não teria o direito de dominar a natureza. Esse mito tem raízes profundas nas grandes religiões, sobretudo na cristã, e está associado à idéia do paraíso perdido (2001, p. 53).

Assim, as narrativas biocêntricas da Revista Nova Escola estão engendradas, especialmente, no diagnóstico da "doença da Terra" realizado no primeiro fascículo. Abaixo, uma foto e um enunciado sobre o rio e a mata Amazônia denotam essa representação cultural de uma natureza paradisíaca, pura.

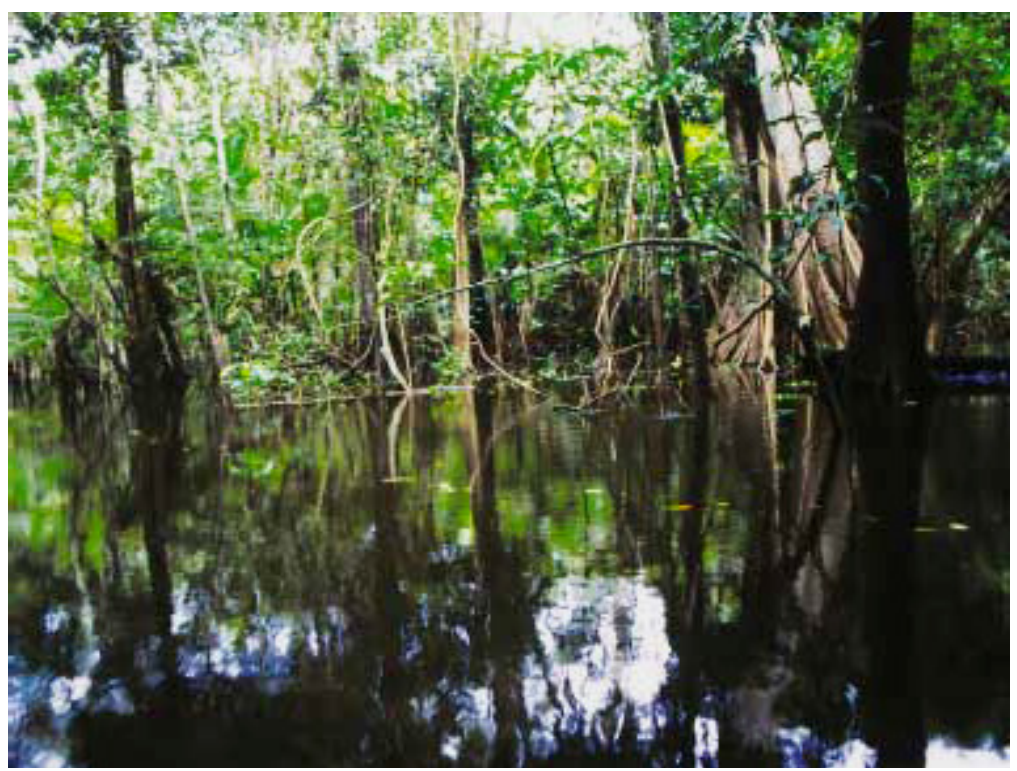

(Figura 1) Ao lado do comentário "Nossas florestas são as mais ricas do mundo em biodiversidade (variedade de espécies animais e vegetais existentes numa região). Na foto, rio e mata da Amazônia", ilustra o primeiro fascículo "A Terra está mesmo doente?" (2003a, 3A) 
ISSN:

Desta concepção teórico-filosófica parte uma das críticas de Diegues relacionada ao turismo ecológico, fonte de economia das sociedades modernas. Nas palavras do autor,

A disjunção forçada entre a natureza e a cultura tradicional, em que os homens são proibidos pelo Estado de exercer suas atividades do fazer patrimonial, e também do saber, representa a imposição de um mito moderno: o da natureza intocada e intocável, próprio da sociedade urbano-industrial sobre mitos das sociedades tradicionais. Nessa linha de pensamento, o chamado "turismo ecológico", realizado em parques e reservas está também imbuído desse neomito de natureza intocada e selvagem. Ao contrário, no entanto, dos objetivos dos primeiros parques norte-americanos, o turismo ecológico é ainda mais elitista, reservado aos que podem pagar tarifas especiais (2001, p. 62).

Essas redes discursivas, materializadas através de princípios e práticas diferenciadas, acabam atuando na manutenção de uma lógica binária e utilitária. Dito de outra maneira, o antropocentrismo e o biocentrismo divulgam a dissociação entre homem/cultura e natureza bem como a necessidade de utilização da natureza pelo homem ou de total desligamento do homem com a natureza.

A lógica binária ou classificatória impulsionou o desenvolvimento da ciência moderna. Assim, recorro a figura de René Descartes, filósofo, físico e matemático francês do século XVII, que propôs uma nova investida do homem sobre a natureza, ou seja, mostrou-o como ser capaz de compreender e operar no meio natural. Para tal, na descrição de seu método, atualmente, denominado método cartesiano, sugeriu a existência de princípios a serem observados na exploração e compreensão do conhecimento matemático: primeiro, o conhecimento decorre de uma construção e/ou reconstrução ao nível do pensamento; segundo, o conhecimento necessita do processo de reconhecimento das leis que constituem o objeto estudado e de suas propriedades e isto implica um trabalho de análise, síntese e enumeração. Certamente, estes princípios garantem que o método cartesiano, num contínuo sistema de controle e verificação, opere na distinção do verdadeiro e do falso (ANDRÉ, 1987).

$\mathrm{Na}$ legitimidade ou falsidade atribuída ao conhecimento matemático inseriu-se um dos princípios do método cartesiano e mais tarde, da ciência moderna: a razão como condição do pensamento humano e da busca da verdade. Neste contexto, a razão mais do que uma faculdade humana tornou-se o único caminho capaz de impulsionar e promover o desenvolvimento da ciência moderna. Conforme Santos (2003), nesse momento, a matemática influenciou diretamente os processos de investigação do conhecimento verdadeiro e instaurou duas conseqüências: o conhecimento depende da quantificação, o conhecimento depende da divisão e classificação rigorosas. A natureza passou a ser objeto de estudo das ditas Ciências Naturais e, decisivamente, separou-se das discussões feitas pelas Ciências Humanas e Sociais.

A lógica utilitária produz tanto a necessidade de utilização da natureza pelo homem quanto o total desligamento do homem com a natureza. A primeira produção está associada ao antropocentrismo; a segunda ao biocentrismo; contudo, elas reforçam a lógica binária e confirmam a dissociação entre a natureza e a cultura. Ora, se o homem pode dominar a natureza ou se a natureza pode fugir dessa dominação, então, a natureza continua sendo representada como alheia, distinta, distante do nosso cotidiano, como o "outro" da cultura, reconfirmando a exposição de Amaral (2000, 2003): 
histórica e culturalmente. E é através dessas experiências intensamente negociadas e disputadas que são estabelecidos os critérios 'de beleza', 'do exótico', 'do sublime', 'do pitoresco', 'do primitivo', 'do inóspito', 'do selvagem', naturalmente 'descobertos' por nós, e adequadamente representados à sociedade. Podemos pensar nos primeiros relatos de viagem - mas poderíamos ir mesmo a tempos e culturas anteriores ao advento das grandes navegações, inicialmente comprometidos com uma literatura fantástica sobre regiões, naturezas e povos distantes, passando pelos estudos científicos dos primeiros naturalistas e viajantes e, também, pelos quadros, desenhos e fotografias dos artistas e das escolas pictóricas que se ocuparam com o tema natureza, até chegar aos mais atuais recursos de produção de imagens e signos utilizados, por exemplo, pela publicidade, pelos filmes de ficção e pelos desenhos animados (AMARAL, 2003, p. 31).

As ilustrações e os registros escritos da Revista Nova Escola - Edição Especial enfocam essa natureza distante da cultura. A apresentação do desenvolvimento e do progresso das sociedades urbanas e rurais esboçada por esta mídia impressa e digital nos seus fascículos demarca essa posição de contrariedade entre o culturalmente "construído" e o supostamente "natural":

Amazônia e Pantanal, paraísos que podem ser salvos (2003f, 1A)

A contaminação dos rios pelo mercúrio utilizados pelos garimpeiros, a caça e a pesca sem controle ou por métodos ilegais, a própria poluição associada ao turismo sem respeito pela natureza também agravam o risco de fazer do Pantanal um paraíso perdido (2003f, 3A)

Esses enunciados reforçam a representação da natureza como paraíso, ou seja, algo "naturalmente" e "divinamente" dado; enquanto que o homem e as suas práticas culturais emergem como causa de todo pecado e, conseqüentemente, como possibilidade de reverter este malefício.

\subsection{0 homem como fonte e solução de todo mal}

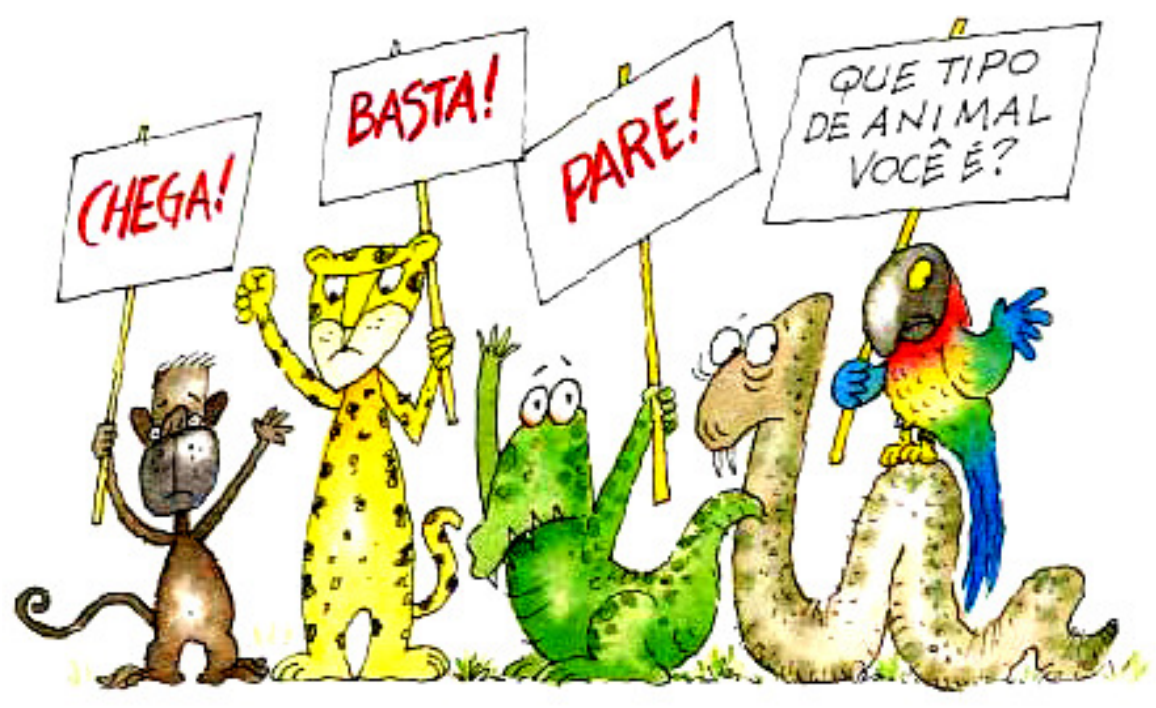

(Figura 2) De Michele lacocca (2003a, 1A), esta figura ilustra a abertura do primeiro fascículo "A Terra está mesmo doente?" 
Ao registrar a natureza como paraíso, a Revista Nova Escola marca o homem e a cultura como pecadores, como fonte e solução de todo mal. Diegues (2001) descreve que o "mito moderno" da natureza intocável resgata a idéia de paraíso perdido, discurso produzido, principalmente, nas religiões cristãs.

No intuito de gerar, produzir esse sintoma de pecado, a figura 2 investe na questão "Que tipo de animal você é?". Isso coloca aos professores e aos seus alunos o imperativo de pensar sobre seus princípios e atitudes, de julgar a si mesmos e aos outros. Assim, as práticas de significação no entorno social conduzem esses sujeitos à aplicação e otimização de suas vidas conforme critérios de juízo estabelecidos previa e cotidianamente. Nas palavras de Larrosa,

A experiência de si implicada na constituição da subjetividade na dimensão do julgar-se seria, então, o resultado da aplicação a si mesmo dos critérios de juízo dominantes em uma cultura. (1994, p. 77).

Ao enunciar o julgar-se, Larrosa (1994) também indica outras dimensões fundamentais que constituem os dispositivos pedagógicos de produção e mediação da experiência de si, ou seja, verse, expressar-se, narrar-se e dominar-se. Na mídia impressa e digital, a dimensão do julgamento parece mais materializada no estabelecimento e na mediação da experiência de si, por isso considero que acionando o julgar-se e o julgar aos outros, a pedagogia cultural sugere a produção pedagógica desses sujeitos. Dito de outra maneira, eles - professores/as e alunos - são colocados a falar, a confessar as formas pelas quais se comprometem ou não com as questões ambientais. Os processos de subjetivação dos ditos "sujeitos do ensino e da aprendizagem" ocorrem na via do governamento ${ }^{1}$ e do auto-governo:

O sujeito pedagógico ou, se quisermos, a produção pedagógica do sujeito, já não é analisada apenas do ponto de vista da "objetivação", mas também e fundamentalmente do ponto de vista da "subjetivação". Isto é, do ponto e vista de como as práticas pedagógicas constituem e medeiam certas relações determinadas da pessoa consigo mesma. Aqui os sujeitos não são posicionados como objetos silenciosos, mas como sujeitos falantes; não como objetos examinados, mas como sujeitos confessantes; não em relação a uma verdade sobre si mesmos que lhes é imposta de fora, mas em relação a uma verdade sobre si mesmos que eles mesmos devem contribuir ativamente para produzir (LARROSA, 1994, p.54-55).

Por isso, as tentativas de ampliação, no capítulo anterior, da noção de pedagogia. As mídias impressas e digitais como pedagogias culturais fazem funcionar representações sobre natureza e cultura, formas de ensinar e aprender e formas de produzir verdades sobre si mesmos nos espaços-tempos sociais.

Dessa perspectiva, a pedagogia não pode ser vista já como um espaço neutro ou nãoproblemático de desenvolvimento ou de mediação, como um mero espaço de possibilidades para o desenvolvimento ou a melhoria do autoconhecimento, da autoestima, da autonomia, da autoconfiança, do autocontrole, da auto-regulação, etc, mas

\footnotetext{
${ }^{1}$ A noção "governamento", cunhada por Veiga-Neto (2005), caracteriza a ação de governar no sentido foucaultiano, portanto, evita associar o termo "governo" ou a expressão "práticas de governo" a uma instância governamental.
} 
como produzindo formas de experiência de si nas quais os indivíduos podem se tornar sujeitos de um modo particular (LARROSA, 1994, p. 57).

Na figura abaixo, uma forma de colocar sob o regime do olhar e do dizer os pecados, os vícios da vida das grandes cidades e, de certa forma, de materializar condição de vida humana versus vida ambiental decorrente dessas práticas culturais. Observe que, diante de fatos ilustrados nas várias janelas do prédio, o homem passa a ser focalizado como responsável pelos danos causados à natureza e à própria vida social.

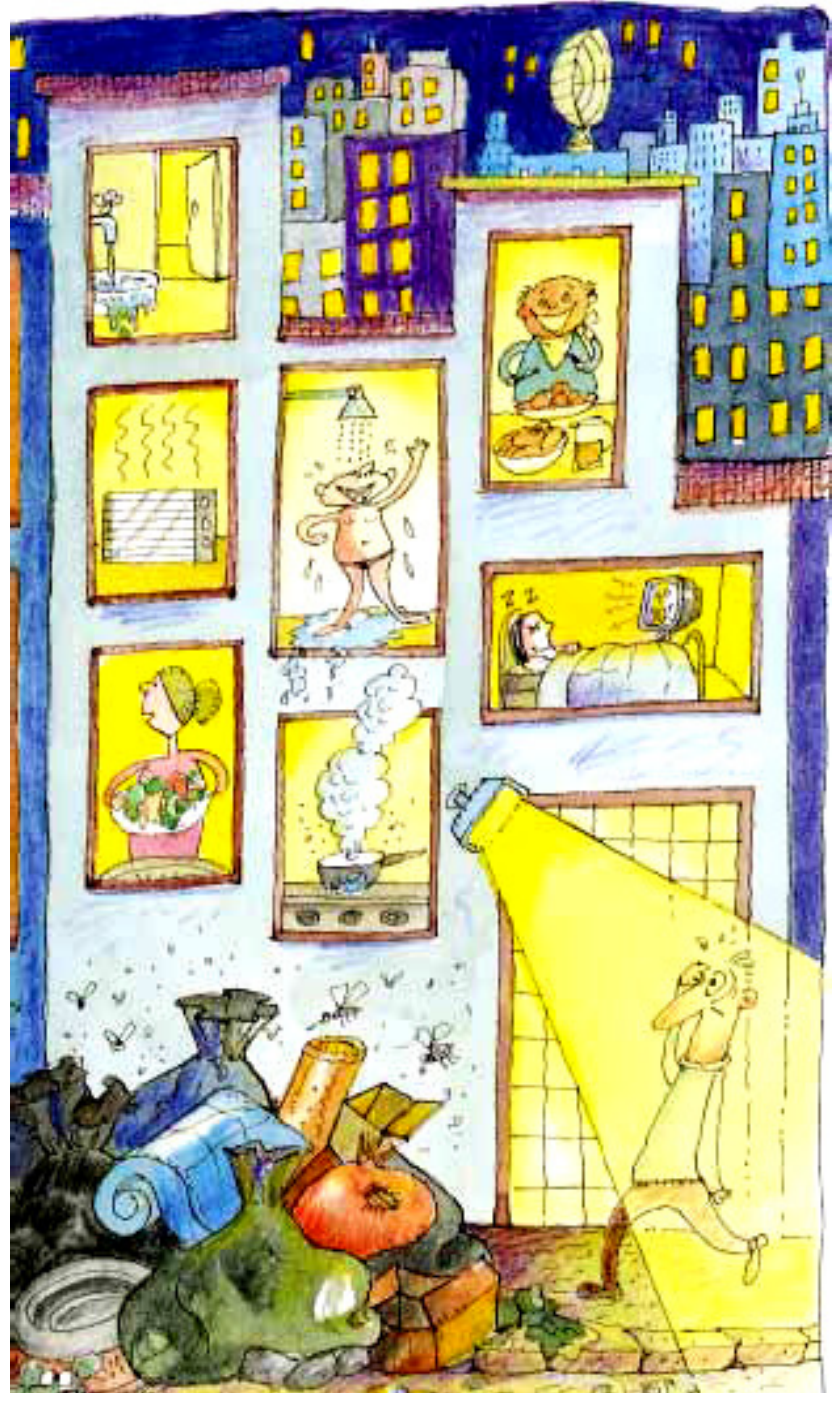

(Figura 3) Ilustração de abertura do quarto fascículo "Consumo e desperdício, os pecados das grandes cidades" (IACOCCA, 2003d, 1A)

Então, nessa produção de verdades, não apenas no âmbito da Educação Ambiental, mas verdades sobre si mesmos, nessa experiência de si, a pedagogia cultural analisada e discutida neste artigo coloca em jogo a lógica das causas e dos efeitos e vice-versa, caracteriza os princípios e as ações humanas num complexo e consecutivo movimento de "fazer o mal" e "receber o mal"; 
"pecar" e, a partir do purgatório social, "ser punido". Abaixo, expressões desta lógica de causalidade e conseqüência:

Carvão: desmatamento e chuva ácida (2003c, 2A)

Petróleo: aquecimento e poluição atmosférica (2003c, 3A)

Ferro e eletricidade: danos ao solo e às águas (2003c, 3A)

Claro, como era de se esperar, nem tudo está perdido. A própria pedagogia cultural cria ou veicula mecanismos para o homem se reconciliar com a natureza, com o projeto divino de um mundo bom para todos. Combate, envolvimento, participação coletiva, recuperação, preservação, eis algumas das palavras ou noções de "ordem ambiental":

(...) para preservar as cidades, precisamos combater os dois maiores pecados da vida urbana: 0 consumo exagerado e o desperdício (2003d, 2A)

A cidade tem cura. (...) A verdade é que mesmo núcleos em estado quase terminal podem ser recuperados. Foi o que aconteceu como centro industrial paulista de Cubatão (2003d, 4A)

Como salvar a Mata Atlântica. Conhecemos a reposta: recuperar e preservar é a saída (2003e, 3A)

Como evoca esta ordem, esses slogans ambientais ou mesmo as representações e as pedagogias culturais problematizadas neste artigo, algumas atitudes são esperadas e desejadas pelos sujeitos. Elas não estiveram sempre neste lugar, nem mesmo surgiram de uma suposta coincidência; essas ordens, slogans, representações e pedagogias foram produzidas nos diversos espaços-tempos sociais, elas adentraram as formas de ver, narrar, expressar, julgar e dominar desses sujeitos professores/as e alunos sendo, por isso, incitados como "formas de fabricar sujeitos ambientalmente comprometidos".

\section{Espaços-tempos escolares: passagens folclóricas pela Educação Ambiental}

“Dia 5 de junho é o Dia Mundial do Meio Ambiente. Uma ótima oportunidade para desenvolver algumas atividades com seus alunos".

Dica aos professores situada no terceiro fascículo "As fábricas e a poluição ambiental” (2003c, 4A)

O chamado acima expressa, em parte, o significado da palavra folclore neste texto. Conforme o Miniaurélio Eletrônico (versão 5.12), folclore significa "o conjunto ou estudo das tradições, conhecimentos ou crenças de um povo, expressos em suas lendas, canções e costumes". Então, no registro desse estudo, passagem folclórica quer expressar o acesso marginal e, muitas vezes, datado às questões ambientais na contemporaneidade. Dito de outra maneira, passagem folclórica quer atribuir sentido à essa prática pedagógica informativa, cronológica, que esboça simploriamente maneiras de ensinar e de aprender na sala de aula de maneira a cultivar 
esse "outro", "exótico", "selvagem " - aqui reside a outra parte, a outra dimensão do significado atribuído à marginalidade da temática da Educação Ambiental nas escolas.

Bem, retomo a primeira dessas partes: as datas comemorativas. Como registrado nos fragmentos formativos, a passagem folclórica pela Educação Ambiental ocorreu, predominantemente, através das datas comemorativas. A feitura de algum cartaz para o "Dia Mundial da Água", o "Dia do Meio Ambiente e talvez para a "Semana Mundial do Meio Ambiente", o "Dia da Árvore", o "Dia da Natureza", o "Dia das Abelhas", o "Dia do Cão", o "Dias das Aves", o "Dia do Mar", o "Dia da Ciência e Cultura", o "Dia do Trigo" etc., ou o ensaio de teatros para apresentar às crianças da rede de ensino particular ou pública são exemplos dessa forma de encarar as problemáticas ambientais.

De certa maneira, esses procedimentos metodológicos são revitalizados pela Revista Nova Escola. A expressão "uma ótima oportunidade" enfatiza essa possibilidade marginal, periférica para trabalhar sobre o meio ambiente. Ainda, reafirma o papel periférico desses temas ambientais, afinal as disciplinas como Língua Portuguesa e Matemática continuam desenvolvendo seus conteúdos programáticos na medida em que questões da ordem do dia, das vivências dos sujeitos escolares e de suas culturas estariam à margem do currículo escolar, à espera de um desses dias "especiais" que já não se configuram apenas como "dias", mas como um ano todo de especialidades. A título de ilustração a demarcação dessas especialidades rotineiras que carregam os sentidos, os significados daquilo que, nas práticas culturais, está sendo tomado como "outro".

Terceira Idade

$1^{0}$. Dia de Santa Terezinha

10. Dia do Vendedor

10. Dia Nacional do Vereador

03. Dia Mundial do Dentista

03 - Dia do Petróleo Brasileiro

03 . Dia das Abelhas

04. Dia da Natureza

04 . Dia do Barman

04. Dia do Cão

04. Dia do Poeta

04. Dia de São Francisco de

Assis

05. Dia das Aves

05. Dia Mundial dos Animais

07. Dia do Compositor

08 . Dia do Nordestino

09. Dia do Açougueiro e

profissionais do setor

10. Semana da Ciência e

Tecnologia

10. Dia Mundial do Lions Clube

11. Dia do Deficiente Físico

11. Dia do Teatro Municipal

12. Dia de Nossa Senhora

Aparecida

12. Dia da Criança

12. Dia do Atletismo

12. Dia do Engenheiro

Agrônomo

12. Dia do Mar

12. Dia do Descobrimento da América

12. Dia do Corretor de Seguros

13 . Dia do Terapeuta

Ocupacional

13. Dia do Fisioterapeuta

14. Dia Nacional da Pecuária

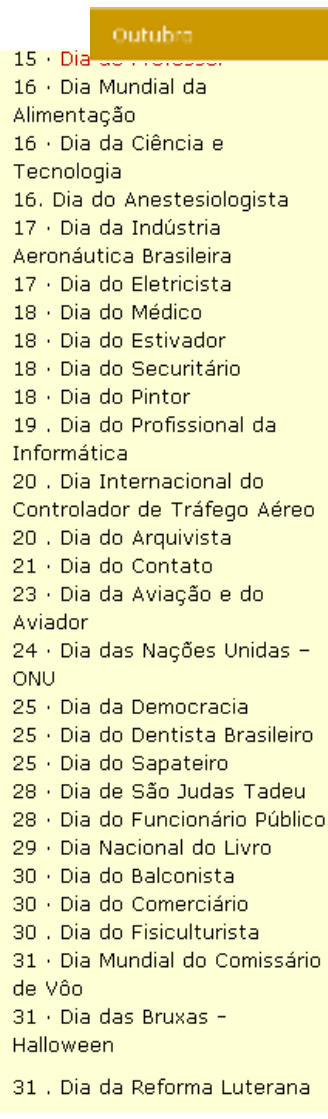

(Figura 5) Calendário do mês de outubro escolhido aleatoriamente e retirado do endereço eletrônico http://www.arteducacao.pro.br/comemorativas.htm 
Em outra experiência intelectual e acadêmica, especificamente, na análise e discussão do planejamento na Educação Infantil (HERMES, 2007) - uma das áreas de minha formação inicial tive a oportunidade de problematizar o planejamento baseado em datas comemorativas. A partir das contribuições teóricas de Ostetto (2006), defendi como esta forma de organização do processo de ensino e aprendizagem está arraigada à perspectiva tradicional e, por isso, como o espaço/tempo escolar resgata as datas comemorativas consideradas importantes para a própria escola.

Independente se este planejamento conduzir a proposta de trabalho implementada na Educação Infantil ou nos Anos Iniciais do Ensino Fundamental, as atividades dele derivadas levarão à passagem folclórica pela Educação Ambiental. Por exemplo, no Dia Mundial dos Animais (cinco de outubro), a professora expõe para os sujeitos-escolares o que significa esta data; elas são levadas a desenhar o animal preferido ou pintar um desenho sobre os animais em extinção; etc.; no outro dia, a professora inicia o trabalho com outra data comemorativa. Além da passagem folclórica, neste planejamento, promove-se a dissociação entre a aprendizagem escolar e os contextos culturais das crianças, pois a cada dia ou semana temos uma data e as atividades que dela decorrem. Outra indicação importante nesta forma de organização do processo de ensino e aprendizagem: apenas são contempladas as datas oficiais ou daqueles que "escreveram a história" e não das pessoas que ficaram silenciadas na mesma (HERMES, 2007).

A perspectiva tradicional que ampara o planejamento baseado em datas comemorativas concebe as relações entre o sujeito e o objeto ou entre o aluno, o conhecimento e o professor apenas numa dimensão unidrecional: transmissão da informação versus recebimento da informação:

\footnotetext{
Dessa forma, utilizando diferentes mecanismos disciplinares (as atividades, os saberes psicológicos, os saberes históricos oficiais), a escola e seus professores possibilitam a produção de um sujeito único, portanto, vinculado à norma, a uma racionalidade linear. A escola passa a ser uma máquina, dentro dela, o planejamento uma ferramenta para governar e produzir "sujeitos" capazes de operar eficazmente na sociedade (HERMES, 2007, p. 05).
}

A outra das partes está vinculada às formas de ensinar e aprender sobre o meio ambiente. Nos fascículos da Edição Especial - "Meio ambiente: conhecer para preservar" (2003), as idéias para a sala de aula demonstram essa necessidade de indicar caminhos, criar receituários - e digase: nem sempre contextualizados e de acordo com os interesses, as vontades da turma - para a prática pedagógica.

Árvore de quê? Conhecer é o melhor caminho para preservar - isso você já sabe" (2003d, 4A)

Voluntários da proteção ambiental. (...) Aliste seus alunos nas fileiras desse vasto exército do bem (2003h, 3A)

Os estratos acima, retirados da "caixa" de idéias para a sala de aula, reiteram a disposição dessa pedagogia cultural de dizer o que passa a ser importante para administrar a suposta "crise ambiental": conhecer. Além disso, formar um exército "do bem". Velhas frases reformuladas para dizer como os sujeitos ambientalmente comprometidos farão para reverter as conseqüências dessa crise ambiental, ou seja, novas formas de delimitar as nossas relações cotidianas com o meio ambiente. 


\section{Pedagogias culturais: forças discursivas na gerência do risco}

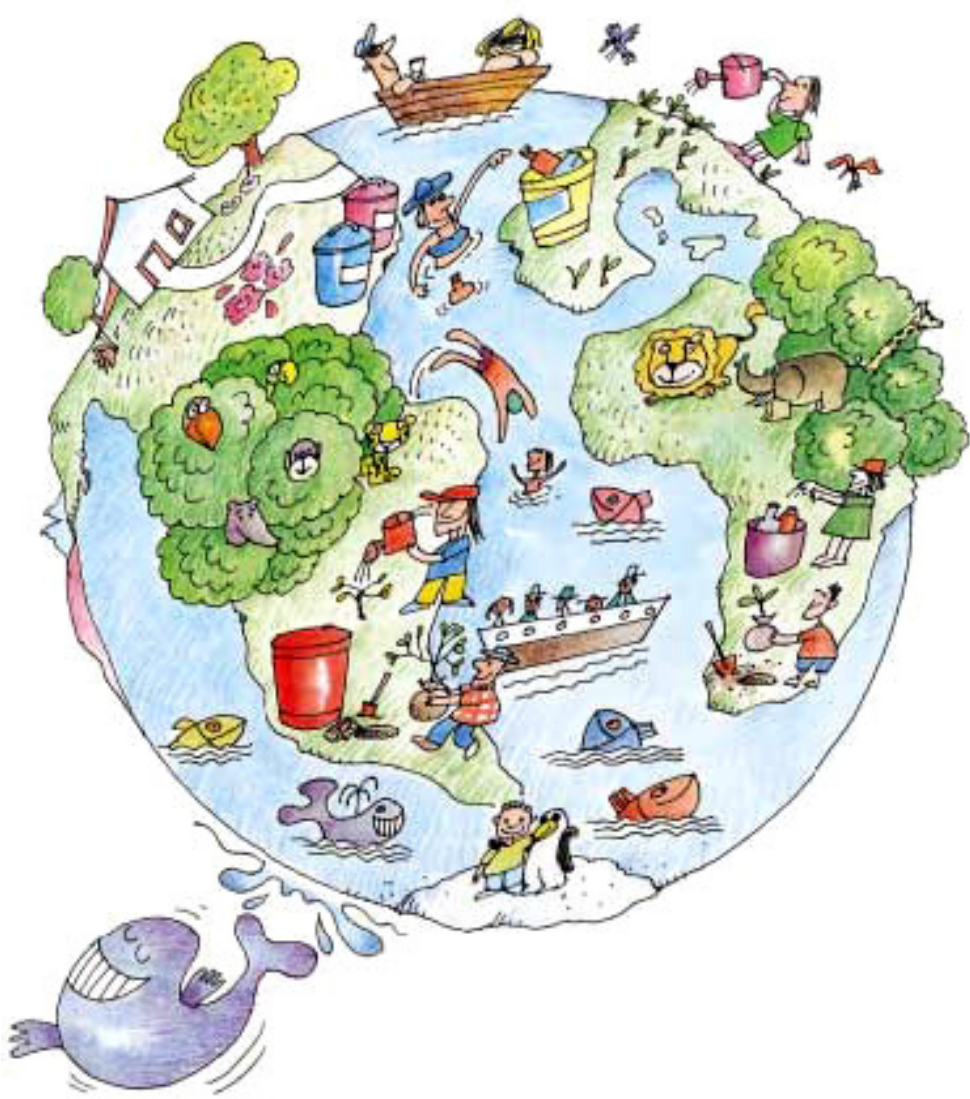

(Figura 4) Na abertura do oitavo fascículo "Um mundo melhor é possível", a ilustração de Michele lacocca $(2003 \mathrm{~h}, 1 \mathrm{~A})$

Eis que chega à hora de pontuar, brevemente, a pedagogia cultural Revista Nova Escola Edição Especial - "Meio ambiente: conhecer para preservar" (2003) como uma potencializadora da gerência do risco. As tentativas anteriores intuíram mostrar como esta pedagogia produz representações dissociadas sobre a relação entre a natureza e o homem, a cultura. Devido à menção aos espaços-tempos escolares, através dos imperativos na comemoração de certas datas ou da participação de todos na busca de soluções para a "crise ambiental", abordou-se como esta mídia impressa e digital legitima formas de ensinar e de aprender nas salas de aulas, mostra como fazer para fabricar "sujeitos ambientalmente comprometidos".

Bem, no momento em que se busca delimitar esta pedagogia cultural e problematizar seus efeitos na educação escolar ou não escolar, cabe retomar uma afirmação esboçada por Amaral em sua Tese de Doutorado:

Essas são questões complexas relativas à produção cultural da natureza, uma produção que tem resultados 'concretos' e 'reais' na qualidade de vida de milhares de seres vivos, na possibilidade de continuidade da vida de tantos outros, na disponibilidade daqueles "recursos" básicos dos quais todos os habitantes do planeta dependem: água, ar e solo (2003, p. 38). 
Considerando a importância desta "natureza produzida culturalmente" na nossa vida cotidiana, na vida das populações, entendem-se os motivos que levam essa pedagogia cultural a identificar possíveis fatores de perigo ambiental a fim de gerenciar o risco.

De Ewald toma-se a noção de risco. Conforme o autor (1991, apud ALMEIDA, 2007), o risco pode ser compreendido como uma ferramenta capaz de permitir o gerenciamento da população através do cálculo, do coletivo e do capital. As estratégias e probabilidades, previsões correspondem ao cálculo; a amostra ou a população perpassadas pelas relações de poder e saber dizem respeito ao coletivo; o processo de perdas e garantias no gerenciamento dessa população está vinculado à noção de capital.

Ao retornar aos estratos da Edição Especial - "Meio ambiente: conhecer para preservar" (2003), a tríade cálculo, coletivo e capital aparece nutrindo a rede discursiva que gerencia o risco sócio-ambiental. Abaixo, uma tentativa modesta de problematizar essa tríade e seus efeitos.

As probabilidades e previsões que correspondem à noção de cálculo são formas de demarcar o passado e projetar o futuro das relações humanas com a natureza:

Em 1950 viviam 2,5 bilhões de pessoas na Terra. No ano 2000 já éramos 6 bilhões - a metade da população que, segundo os especialistas, o planeta pode abrigar nas atuais condições. E se hoje, segundo a ONU, cerca de 1,3 bilhão de pessoas já não têm acesso à água potável, o quadro só tende a se agravar (2003a, 2A)

Muita gente acha que o brasileiro é um individualista interessado em levar vantagem em tudo. Mas não é bem assim. Cerca de 20 milhões de pessoas - entre as quais mais de 8 milhões de jovens com idades entre 15 e 24 anos - prestam serviços voluntários em ONGs e entidades filantrópicas do país (2003h, 3A)

Nota-se, neste ínterim, que se trata de informar sobre os perigos que assolam a vida no planeta Terra - no caso, a problemática da falta de água - e que dependem, predominantemente, das ações humanas como, por exemplo, a participação em voluntariados em campanhas nãogovernamentais e/ou filantrópicas. Os números, então, são estratégias para garantir o quadriculamento dos problemas e o controle das atividades humanas.

O segundo elemento da tríade, o coletivo, opera com a amostra ou a população. Nos estratos escolhido e apresentados a seguir estão em pauta as espécies do ecossistema brasileiro e a "multiplicação da espécie humana":

No Brasil, campeão mundial em número de espécies, dois ecossistemas encontram-se em situação crítica: a mata Atlântica e o Cerrado, que figuram na lista dos 25 ambientes mais ameaçados do mundo.A biodiversidade ameaçada. (2003a, 3A) 


$\begin{array}{lr}\text { Ano } & \mathbf{N}^{*} \text { de pessoas } \\ 8000 \text { a.C. } & 5 \text { milhoes } \\ 4000 \text { a.C. } & 86 \text { milhoes } \\ 1 \text { da ara crista } & 133 \text { milhóes } \\ 1650 & 500 \text { milhoes } \\ 1825 & 1 \text { bilhao } \\ 1930 & 2 \text { bilhües } \\ 1950 & 2,5 \text { bilhoes } \\ 1975 & 4 \text { bilhoes } \\ 1990 & 5,3 \text { bilhoes } \\ 2000 & 6 \text { bilhóes }\end{array}$

Existem no ecossistema brasileiro:

- mais de 10 mil espécies de plantas

(5 mil endêmicas);

- aproximadamente 1 milhão e 600 mil

espécies animais, incluindo insetos;

- 261 espécies de mamíferos (73 endêmicas);

- 620 espécies de pássaros (160 endêmicas);

- 260 espécies de anfíbios (128 endêmicas) (2003e, 3A)

Entrelaçadas em relações de poder e saber, essas organizações das amostras ou populações trabalham no sentido de mapear trajetórias de crescimento demográfico e garantir projeções futuras para melhor qualidade de vida das populações: quais os ecossistemas que sofrem com a ameaça humana? Como ocorreu o crescimento demográfico que, atualmente, oferece conseqüências à vida da espécie humana? Quais as espécies cartografadas no ecossistema brasileiro? O que elas oferecem à vida humana? Quais as vantagens ou lucros? Essas são perguntas que oferecem condições de tramar respostas, visualizar os riscos, as perdas e as garantias no terceiro elemento da tríade.

O capital no gerenciamento da população repercute de maneira produtiva nos documentos analisados e discutidos neste artigo. Trata-se de uma série de estratos que colaboram no delineamento dos efeitos dos problemas trazidos pela industrialização, pela problemática da água contaminada, da atuação desordenada das madeireiras nas florestas brasileiras:

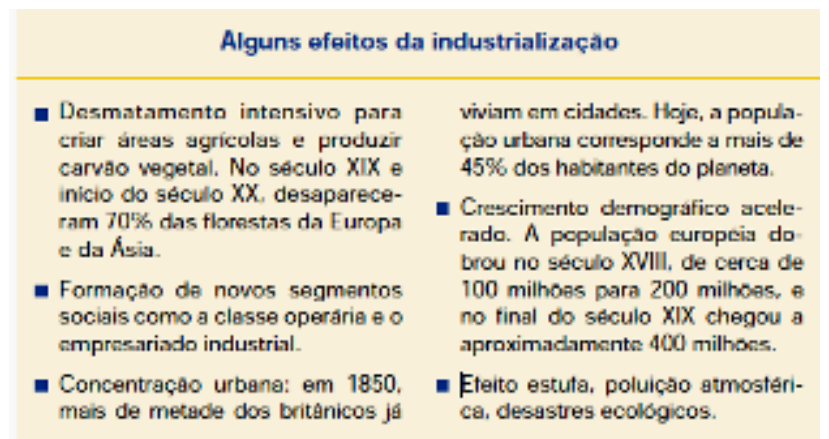


Em 1998, morreram 36 em cada grupo de 1000 crianças brasileiras, em muitos casos devido a diarréias e outras doenças disseminadas pelo líquido contaminado (2003d, 2A)

A atuação das madeireiras, que também dizem contribuir para o progresso da região, revela o mesmo imediatismo e igual descaso em preservar recursos naturais. Apenas 35\% da madeira cortada na Amazônia é vendida e transformada em casas e móveis. Outros $22 \%$ viram carvão. O restante se perde: para cada árvore derrubada que chega a uma serraria, 27 caem inutilmente (2003f, 2A)

Mas, de certa forma, trata-se de estratos que mostram as garantias que trazem determinadas ações humanas, dos ganhos e dos lucros dessas ações preventivas e conservacionistas:

\begin{abstract}
“A partir de 1984, implantou-se na área um amplo programa de controle de poluição. As indústrias foram obrigadas a instalar filtros nas chaminés e a realizar um tratamento nos seus resíduos líquidos; milhares de árvores foram plantadas nas encostas da Serra do Mar, onde a chuva ácida havia destruído a vegetação. Com isso, eliminaram-se $81 \%$ dos poluentes atmosféricos (...)". (2003d, 4A)
\end{abstract}

\begin{abstract}
Hoje, no Brasil, o mesmo interesse econômico responsável por tanta devastação defende a preservação do nosso patrimônio natural. E que patrimônio! Pesquisas divulgadas em 1991 estimaram o valor da biodiversidade brasileira em 2 trilhões de dólares, ou seja, quatro vezes o PIB do país. Outros estudos calcularam que a exploração equilibrada da Amazônia poderia render anualmente mais de duas vezes o PIB brasileiro. Só as indústrias de medicamentos e cosméticos, baseadas na biodiversidade local, gerariam 500 bilhões de dólares por ano. (2003g, 2A, 3A)
\end{abstract}

Neste último estrato, a biodiversidade brasileira passa a ser tratada como recurso, como fonte de lucro para a nação brasileira, melhor, para aqueles poucos pesquisadores que detêm as fórmulas, os mecanismos de extração dos recursos naturais existentes no território brasileiro.

Então, as forças discursivas que sustentam a tríade cálculo, coletivo e capital no gerenciamento do risco sócio-ambiental, dispõem alguns imperativos para a população brasileira, para aqueles professores/as e alunos/as que, nas salas de aulas, organizam práticas pedagógicas capazes de oferecer soluções locais ou regionais para a "crise ambiental", as problemáticas ambientais anunciadas e divulgadas amplamente nas tecnologias de informação e comunicação, nas pedagogias culturais.

Notícias como essas estão nas manchetes dos jornais todos os dias. E confirmam: sim, a Terra está doente. (...) Neste encarte - que abre a nossa série sobre o Meio Ambiente - vamos fazer um diagnóstico da saúde do planeta (2003a, 1A)

(...) vamos dizer como tentar trazer de volta a saúde do planeta. E como você e seus alunos podem participar desse 'tratamento intensivo' que a terra está precisando. Acompanhe-nos! (2003a, 2A) 
(...) a revolução ambiental está acontecendo. Trata-se de uma ampla mudança de comportamento que envolve o poder público, a Organização das Nações Unidas (ONU) e outras associações internacionais, empresas privadas, ONGs, entidades filantrópicas e milhões de voluntários, unidos em nome da preservação dos recursos do planeta. E tudo começa por uma transformação individual de hábitos: afinal, se cada um fizer a sua parte, já será meio caminho andado (2003h, 1A)

Reciclar é preciso. Para mobilizar os alunos e suas famílias é importante fornecer informações sobre o reaproveitamento do lixo $(2003 \mathrm{~h}, 2 \mathrm{~A})$

A pedagogia cultural, ao tramar o gerenciamento do risco, produz efeitos na configuração das práticas pedagógicas desenvolvidas na educação escolar ou nas instâncias não escolares: incentiva a preservação e a conservação ambiental como medidas necessárias para a qualidade de vida no planeta Terra, coloca os/as professores/as e os/as alunos/as como "sujeitos ambientalmente comprometidos", mesmo que para essa fabricação tenha que divulgar passagens folclóricas pela Educação Ambiental, dissociar as relações entre a natureza e o homem/cultura, colocar a natureza como o "outro", distante das nossas relações cotidianas.

\section{CONSIDERAÇÕES FINAIS}

Os caminhos e (des)caminhos percorridos no processo formativo-investigativo ofereceram condições para pensar a Educação Ambiental, a formação de professores/as, a fabricação de "sujeitos ambientalmente comprometidos" através de passagens folclóricas pelas questões ambientais, pelo gerenciamento do risco nas pedagogias culturais. Então, abaixo, proponho algumas contribuições deste e outros trabalhos acadêmicos para pensar a relação entre a natureza e a cultura bem como a fabricação de "sujeitos ambientalmente comprometidos":

Primeiro, falar sobre o que nos acontece nos espaços-tempos formativos torna-se uma das maneiras de mostrar a produtividade dessas instâncias, de afirmar como também produzimos representações e pedagogias escolares ou culturais, como colaboramos na produção de verdades na Educação Ambiental.

Segundo, desconfiar das mídias impressas e digitas que mantêm e divulgam a lógica binária e utilitária da relação homem/cultura e natureza, impulsionam a produção de verdades dos sujeitos escolares sobre si mesmos; problematizar os grandes chamados midiáticos que oferecem caminhos, receitas às práticas pedagógicas na formação de professores/as tramando as passagens folclóricas pelas questões ambientais torna-se uma medida capaz de produzir outros saberes, outras práticas em Educação Ambiental, afinal nossas salas de aula são constituídas por diferentes grupos culturais, que estabelecem relações muito específicas com a natureza e que por ela são diretamente definidos e perpassados.

Terceiro, discutir os efeitos produzidos pela pedagogia cultural na formação de professores/as, tensionar as implicações desse "elixir pedagógico" destinado à educação de crianças e jovens, pode contribuir significativamente com as relações estabelecida entre esses sujeitos escolares e o meio. 
ISSN:

\section{REFERÊNCIAS BIBLIOGRÁFICAS}

ALMEIDA, Francis Moraes de. A emergência do conceito de risco no debate sociológico contemporâneo. XII Congresso Brasileiro de Sociologia, GT 28 - Teoria Sociológica, UFPE. Recife, Pernambuco: 29 de maio a 1 de junho de 2007.

AMARAL, M. B. Natureza e representação na pedagogia da publicidade. In: COSTA, M. V. (org.). Estudos Culturais em educação: mídia, arquitetura, brinquedo, biologia, literatura, cinema... Porto Alegre: Editora da UFRGS, 2000.

. Histórias de viagem e a produção cultural da natureza: a paisagem do Rio Grande do Sul segundo os viajantes estrangeiros do século XIX. Tese de Doutorado. Porto Alegre: UFRGS, 2003.

ANDRÉ, J. M. Renascimento e Modernidade: do poder da magia à magia do poder. Coimbra: Livraria Minerva, 1987.

ARAÚJO, M. I. de. A universidade e a formação de professores para a Educação ambiental. In: Revista Brasileira de Educação Ambiental. Brasília: Rede Brasileira de Educação Ambiental, 2004, p. 71-78.

SANTOS, B. S. Um discurso sobre as ciências. 14a Edição. Porto: Edições Afrontamento, 2003.

CORREA, G. C e PREVE, A. M. Ecologia de rebanho. In: CORREA, G. C e PREVE, A. M (orgs.). Ambientes da ecologia: perspectivas em política e educação. Santa Maria: Editora da UFSM, 2007.

DIEGUES, Antônio Carlos Santana. Os mitos bioantropomórficos, os neomitos e o mundo natural. In: $\mathbf{O}$ mito moderno da natureza intocada. São Paulo: HUCITEC, 2001, p. 53-62.

FOUCAULT, M. Verdade e poder. In: Microfísica do poder. Rio de Janeiro: Edições Graal Ltda, 2001, p. 0114.

. Os intelectuais e o poder - Conversa entre Michel Foucault e Gilles Deleuze. In: Microfísica do poder. Rio de Janeiro: Edições Graal Ltda, 2001, p. 69-78.

HERMES, S. T. Planejamento na Educação Infantil: aberturas, posições, possibilidades. In: FISCHER, B. T. D., EGGERT, E., CUNHA, A. (orgs). Anais do 5o Congresso Internacional de Educação, 20 a 22 de agosto de 2007, São Leopoldo, RS. Pelotas: Seiva Publicações, 2007, p.01-10.

LARROSA, J. Tecnologias do eu e educação. In: SILVA, T. T. da. 0 sujeito da educação: estudos foucaultianos. Petrópolis, Rio de Janeiro: Vozes, 1994, p. 35-86.

OSTETTO, L. E. Planejamento na Educação Infantil... Mais que a atividade. A criança em foco. Disponível em http://www.komarca.com.br/diariodacreche/planejamento_na_educ.htm. Acessado no dia 02 de agosto de 2006.

REVISTA NOVA ESCOLA. A terra está mesmo doente? Abril, 2003a. Edição Especial: Meio ambiente: conhecer para preservar. 
ISSN:

As primeiras cidades, o primeiro lixo. Maio, 2003b. Edição Especial: Meio ambiente: conhecer para preservar.

. As fábricas e a poluição ambiental. Junho, 2003c. Edição Especial: Meio ambiente: conhecer para preservar.

. Consumo e desperdício, os pecados das cidades grandes. Agosto, 2003d. Edição Especial: Meio ambiente: conhecer para preservar. preservar.

O homem e a natureza no Brasil. Setembro, 2003e. Edição Especial: Meio ambiente: conhecer para

Amazonas e Pantanal, paraísos que podem ser salvos. Outubro, 2003f. Edição Especial: Meio ambiente: conhecer para preservar.

Brasil: a maior potência ecológica do mundo. Novembro, 2003g. Edição Especial: Meio ambiente: conhecer para preservar.

Um mundo melhor é possível. Dezembro, 2003h. Edição Especial: Meio ambiente: conhecer para preservar.

ROCHA, C. F. O espaço escolar em revista. In: COSTA, M. V. (org.). Estudos Culturais em educação: mídia, arquitetura, brinquedo, biologia, literatura, cinema... Porto Alegre: Editora da UFRGS, 2000.

VEIGA-NETO, A. Governo ou governamento. In: Currículo sem fronteiras, v.5, n.2. Julho a Dezembro de 2005, p. 79-85.

VEIGA-NETO, A. e WORTMANN, M. C. Estudos Culturais da Ciência \& Educação. Belo Horizonte: Autêntica, 2001. 